\title{
Discussion on Library's "Micro" Service Mode under Micro Information Environment
}

\author{
Qiuping Chen \\ Weifang University Library, Weifang 261061, China \\ wfuchenqp@126.com
}

Keywords: micro information environment library micro service mode of service

Abstract: With the rapid development of mobile Internet, people have entered the age of micro information. Micro-information environment is a dynamic and open information ecosystem composed of people, micro-information content and micro-information technology. Its main characteristics are embodied in the "miniaturization" of information media, information carriers, information content and information activities. The library service under the micro-information environment has the characteristics of fragmentation of service content, fine service form, mobile service segment, interactive service process and ubiquitous service scope.

\section{Introduction}

With the rapid development of mobile Internet, people have entered the era of micro-information. The micro-information environment makes the library's "digital ecosystem" gradually change to "micro-information ecosystem". In the new micro-information environment, knowledge and information are not only stored in bookshelves, archives, libraries or the minds of experts, but also gathered in large-scale data network system, and widely used and disseminated in the form of information fragments and information blocks. A huge amount of information is scattered in the vast ocean of information in fragmented micro-forms. How to adapt to the changing micro-information environment and effectively help users to obtain and use information has become an important issue in the development of library services in the micro-information era. The wide application of smart phones and mobile readers provides a new way for library services in micro-information environment. Libraries can use mobile Internet technology to meet the information needs of users in micro-information environment in the form of "micro" services. Library "micro" service is a kind of user-centered, relying on mobile Internet and all-media information technology, through convenient mobile communication equipment and reading terminals, to provide users with graphic content fragmentation, fine service, process interaction, and a wide range of personalized information services. Information service under traditional environment is often a kind of "macro" service mode which seeks to be large and complete. This has already been difficult to satisfy the users' information demand under micro-information environment. The new micro-information environment library service embeds library resources and services into the process of users' study, work and scientific research, and provides users with professional and fast services. 


\section{Overview of micro information environment}

\subsection{The concept of micro information environment}

Micro information environment is a new concept closely related to mobile information technology. The concept of micro information environment was first proposed in the first International Conference on micro learning in 2005. It is a dynamic and open information ecosystem composed of people, micro-information content and micro-information technology. It is a learning environment that uses modern information technology to acquire knowledge content. It can help users to go deep into other simultaneous work to acquire knowledge and application knowledge [2]. Nowadays more and more people use mobile phones to surf the Internet. We are entering a new era of micro-information environment. Knowledge, information, communication and so on have evolved into tiny pieces of digital information, which are connected by pieces of information. It is loose and dynamic reorganization, and continuously generates a lot of new information, data, tasks and clues [3]. These vast amounts of loose and constantly reorganized fragments of information eventually aggregate into a huge micro-information world, that is, micro-information environment. Micro-information environment is actually one of the important components of ubiquitous information environment. It consists of portable micro-devices (mobile terminals), micro-content (fragmented information), micro-application software and secure Internet.

\subsection{Characteristics of micro information environment}

The main characteristics of microinformation environment are embodied in the "miniaturization" of information media, information carriers, information content and information activities. (1) Information media miniaturization. In the micro-information environment, people use mobile information devices (such as mobile phones, hand-held readers), the media of information dissemination has become a "pocket media", the media of information dissemination is developing towards miniaturization. Cell phones and other micro information devices are just like keys. Especially with the continuous promotion of smart phones and mobile readers, the operating system is becoming more and more convenient and easy to use. (2) Information carrier is miniaturized. With the rapid development of digital information technology, the carrier of information content changes from physical paper to virtual digitization. A handheld reading terminal can carry thousands of books, which is equivalent to a small library. (3) Iinformation content is miniaturized. Information in micro-information environment is micro-content, which is released in the form of short fragments, is the smallest independent information unit on the Internet, with the characteristics of independence, self-contained, elementary, data format. The information content in traditional environment is generally presented in an integrated way. (4) Information activities are miniaturized. In the micro-information environment, the information activities of users are developing towards miniaturization, such as "micro-blog", "micro-learning" and "micro-reading". These micro-information activities mainly focus on the small dimensions of information and learning process, fully reflects the concept of learning ubiquitous, information ubiquitous, through simple and easy-to-use real-time communication, the formation of personal micro-messaging community, micro-information exchange, to achieve real-time information sharing [4].

\section{3. "Micro" characteristics of library services under micro information environment}

\subsection{Service content is miniaturized}

In micro-information environment, users make use of information by mobile mode. The 
utilization time is fragmentary, and usually does not concentrate on a complete period of time to systematically read and learn, but more time is always used on the road, on the car or at work. This makes the use of user information in time presents a scattered, non-fixed, fragmentary characteristics [5]. This will inevitably lead to the miniaturization and fragmentation of information utilization content, because users prefer short, refined micro-information content in clips of time, such as an information clip, a novel, a micro-blog speech or even a dynamic image or expression.

According to the fragmentation of information utilization time and the miniaturization and fragmentation of content, the library should integrate and process all kinds of scattered information to form diversified miniature and delicate fragmentation of information content, so that users can accept the miniature service of the library in limited fragmentation time. The miniaturized and fragmented content here is not disordered, but ordered information fragments processed by libraries, which are deliberately crushed for better use by users in micro-information environments.

\subsection{Fine service form}

In the era of knowledge-based economy, knowledge is the driving force of innovation and development, and the pressure of people to learn knowledge is multiplied, while the fast pace and tense pace of life and work make people not have enough time to learn. The mobile acceptance of micro information environment provides a convenient condition for fast-paced learning. In the micro-information environment, in order to save time and grasp knowledge quickly, micro-learning, which has a short duration and aims at primary learning units, has become a favorite way of learning. In order to meet the needs of Micro-learning readers for library information, libraries need to change the large and all-round traditional information services in the past, establish a scientific and easy-to-use micro-service mechanism, and carry out meticulous and detailed services in accordance with the individual information needs of users. In the micro-information environment, the content of users' needs is more fragmented. The National Library must establish a more perfect, timely and detailed service system and mechanism to provide users with a full range of micro-services, differentiation and personalization.

\subsection{Mobile service means}

At present, the mobile Internet is everywhere, and various mobile communication devices (such as iPad, smart phones) are becoming more and more popular. Mobile information terminals have become a necessary tool for people to carry around. According to the statistics published by China Internet Network Information Center in July 2012, the number of mobile Internet users in China surpassed that of computer users in the first half of 2012, with 388 million mobile Internet users and 380 million desktop computer users. More people no longer stick to the computer to communicate with the outside world, but through the lavish hand-held communication tools anytime, anywhere on the Internet access to information. It brings the user's information needs at will, anytime, anywhere, users want to be able to get answers whenever and wherever they encounter problems. After dinner and on the way to work, users are accustomed to handheld mobile communication equipment to exchange information with the outside world, and get the information resources needed at any time.

\subsection{Interaction of service processes}

The micro-information environment provides great convenience for people to care about the things around them. People are also more concerned about the subtle changes of things around them. Social focus, new things, new ideas and new viewpoints are all the issues that people care about. 
Users require timely dissemination of information, but also want to participate in hot spots, focus interaction, to personally experience the truth of the matter, to understand more details, for their own learning work to provide first-hand reference. Therefore, the library services in the micro-information environment will be more interactive online services, so as to facilitate timely communication between users and librarians, user needs to express more clearly, librarians provide more accurate answers. Interactive service can also realize the exchange and collision between users, librarians and other people, stimulate their own inspiration and improve their own shortcomings. At the same time, library interactive services should be seamlessly embedded in the daily work and learning process of users, so that users can accept library services without leaving the daily environment.

\subsection{Ubiquitous service area}

In the micro-information environment, the network is everywhere, the library service is everywhere, showing a ubiquitous trend. Because of the ubiquitous mobile information receiving terminal, the library service can be extended to any corner. As long as the intellectual property law is not violated, library services can achieve all-round and all regional services. Libraries can make full use of Web 2.0 and information ubiquitous technology to maximize the scope of Library services. Make full use of QQ, MSN, SNS and other ubiquitous network communication platform and virtual social tools, so that the scope of library services to extend to the entire network world.

\section{4. "Micro" service mode of Library under micro information environment}

\subsection{Build a new concept of "micro" service}

There are great differences between the micro-information environment and the traditional information environment in content and form. The library must innovate the service concept and construct the "micro" service concept to meet the requirements of the new environment in order to meet the requirements of the new situation. We should always be user-centered, fully rely on all kinds of modern, especially mobile Internet information technology, micro-service into the library's overall service system, clear micro-service post responsibilities, to provide users with personalized, subtle and comprehensive information services. We should abandon the large and all-round, empty and extensive "macro" service in the past, go deep into users, participate in the process of users'information activities, provide users with detailed "micro" services, and integrate library services into users' learning, work, scientific research and living environment in various forms of "micro" services. In the process of library's "micro" service, it still sticks to the "user-centered" service tenet, dismantles the past library's "macro" service chain, restores it to the specific service department posts, forms a detailed service content unit, further refines the service responsibilities of each department, and clarifies each content. Service objectives and standards of the unit, and then according to the personalized characteristics of different information users, the relevant service units are combined to actively provide services for users [7]. Of course, the separation of the service chain is not arbitrary, and the service departments can not do their own work, but under the guidance of a unified library service objectives and concepts, give full play to the strength of each service unit to jointly build a library "micro" service system.

\subsection{Provide accurate "micro" service content}

Because people use information randomly and fragmentarily in the micro-information environment, it also brings fragmentation of the content of information needs, so libraries should 
adapt to the specific needs of users in the service content, and provide users with small fragmented "micro" content. The so-called "micro" content is relative to the macro content (overall content) provided by the Library under the traditional information service environment. It is the individualized, subtle, decentralized and fragmented service content provided by the Library under the micro-information environment according to the characteristics of users' needs. It can be a sentence, a picture, a sound [8]. In the micro-information environment, libraries should be good at perceiving users' potential information needs, scientifically analyzing users' information utilization and demand psychology, providing users with meticulous and accurate "micro" information content, so that "each reader has its own information". In the process of providing micro-content services, libraries should classify information groups according to the personalized characteristics of users, understand the information needs of each user, and actively push relevant "micro" information content for them. For example, to provide the elderly groups with physical fitness, recuperation and other common sense, to provide education films or puzzle games for children.

\subsection{Building an open micro service platform}

After years of digital construction, with the further development of network information technology, the current library service network basically has the hardware and software conditions to carry out micro-content services. Blog, micro-blog, RSS, BBS, SNS, QQ, the most popular micro-content dissemination tools have been widely used in the field of library, making it possible for library services embedded in the user environment to carry out micro-content services [[9]. At present, popular micro-content aggregation tools are Tag, RSS, Friendfeed, etc. It reduces the cost of user information selection and screening, and provides an efficient micro-information utilization environment. However, the content of these tools is often not classified scientifically, but is classified, filtered and sorted by users themselves. As a specialized information organization, libraries should create an open "micro" content service platform which is user-oriented, social-oriented, orderly and can embody the characteristics and professional advantages of libraries. Through this service platform, micro-content on the external network can be integrated into the overall information system of Libraries in an orderly manner and scientifically. Standard classification and organization methods process and organize all micro-content, generate library's own micro-content and push it to all social users [10]. This library service "micro" platform is interactive, equal, open and personalized, and users can participate freely without barriers. According to the present situation of library network technology, we can adopt the following ways: first, we can set up a special subject database in the way of Web, and set up a micro-content service zone on the existing library web site to provide download services; second, we can set up a WAP website in the way of WAP, and users can use mobile Internet devices such as mobile phones and laptops directly. Visit the W AP website of the library, browse and download related resources; third, RSS mode, through service booking, the library provides push service for users. At present, Shanghai Library, National Library and Tsinghua University Library have begun to establish mobile library or mobile library to carry out such services.

\subsection{Create a good "micro" service atmosphere}

The concept and mission objectives of Library's Micro service are mainly realized by service micro reading. Micro-reading is a kind of fragmented reading mode, which is based on the fragmented micro-information (such as short messages, micro-text, network short style) through mobile reading facilities. Its content includes text, text, pictures, audio, video and other information symbols that can record knowledge. Network links allow all these fragmented information symbols to be dispersed and aggregated to form a multimedia form of micro-information content [11]. 
Reading these micro-information doesn't need to be sitting in the library reading room. It can read, listen and write at any time and place, and communicate with people thousands of miles away. Therefore, under the micro information environment, the library must create a good micro reading atmosphere for users. Libraries should make full use of modern mobile Internet and digital information technology to create a seamless link environment between reading tools such as computers, mobile phones, readers and the Internet, and create a good "micro" atmosphere for micro-reading and library micro-service so as to meet the needs of the fast pace of social life in the micro-information environment. This not only enriches the reading itself, but also is an effective way to expand the library service function, expand the scope of service and attract more potential users.

\section{Concluding remarks}

In the age of Internet, the "non-centralization" of information has changed the traditional mode of one-way information dissemination, and realized the networking and interaction of information dissemination. The miniaturization of information media, carriers, contents and activities under the micro-information environment will surely bring about the change of library service characteristics and trends. In the micro-information environment, in order to meet the needs of the development of this trend, libraries must innovate the service mechanism, service mode and service process, reform the traditional "macro" information service mode, and timely launch the library "micro" service needed by users to meet the needs of information users under the new situation. The micro-information environment brings not only the extension of service contents and the innovation of service modes, but also the deepening of users'participation in Library services; it brings not only the progress of technology, but also the updating of service concepts and the evolution of Library culture. Library "micro" service is an open, friendly, participatory and interactive service mode. It will make readers enjoy more convenience and happiness of information utilization and provide a strong vitality for the development of Library services.

\section{References}

[1] Guo Wenli, Zhao Yaxin, Yan Chaobin. Exploration of Library Microinformation Ecological Environment [J]. Library and Information Work, 2013 (8): 12-16

[2] BTUCk P A. Microlearning as strategic research field: An invitati-on collobarate (Introductory Note) [C\}//llug "f, Lindner M, J3TUCk 1'A. Proceedings of the 1 st Intemational Microleaming 2005 Conference. Innsbruck: Innsbmck Gniversitv Press, 2005:1317

[3] LlndneT'M. LeaTTnng In n11CT'Onledla env1T'OnmentS7 (IntroductoTy-Note [C\}//llug "f, Lindner M, J3ruck 1'A. Proceedings of the 2nd International Microleaming 2006.Innsbruck: Innsbmck Gniversitv Press, 2006:1719

[4] Lindner M. lluman-centralized design for 'casual'infoTxnation an-d 1 eaTTnng In n11CT' Onledla env1T'OnmentS [\} //1101Z1ngeT'A.et.al Proceedings of the 2nd Symposium of the WG 11C1\&amp;GL, of the Aus-trian Computer Society.Sydney: Austrian Computer Society, 2006:52 One 60

[5] Fragmentation Studies by Tao Kan, Editor of the Mid-term Journal from the Perspective of Microage [J]. Journal of Zhejiang Wanli University, 2012 (5): 57-61

[6] China Internet Information Center. 30th China Internet Development Statistics Report [EB/OL]. Http://www.cnnic.net.cn/hlwfzyj/hlwxzbg/hl-wtjbg/201207/t20120723 32497.htm.

[7] Liu Liping, Pang Caiyun. Library micro service research [J]. library construction, 2013 (4): 60164

[8] [10] Andong Mei, Geng Xiaoguang. Microcontent: Long Tail of Library Service [J]. Library Construction, 2010 (12) 54156

[9] He Yanning, Zheng Jianming, Hu Tangming. Research on "Long Tail" of Library Users in China from the Perspective of Humanistic Spirit [J]. Library Forum, 2009 (4): 19-21

[11] Zhang Ying micro service: building [J]. Library of "blue ocean" to create library services, 2011 (7): 51 one 53 